\title{
Gender differences in adaptive reactions of students in the development of educational innovations as a factor of sustainable development
}

\author{
Tatyana Bashkireva* and Anastasia Bashkireva \\ Ryazan State University named after S.A. Yesenin, 390000 Ryazan, Russia
}

\begin{abstract}
The sustainability of the development of society depends and is secure by the safety of health of human capital. The article presents the results of a study of gender differences in adaptive reactions of students in the development of educational innovations using the non-invasive method of heart rate variability. Comparative analysis of heart rate measurements among the surveyed students showed that both boys and girls had tachycardia during the lessons. In boys, an increase in the stress index revealed that was reliably associated with the tension of the parasympathetic system, and in girls - the sympathetic system of autonomic regulation of heart rhythm control. A wide individual range of adaptive reactions of the cardiovascular system of young men and women to the impact of ICT revealed. The data obtained more indicative of biological (sex) differences in adaptive responses in the implementation of information technology in education. Our research has shown gender differences in adaptive responses. We observed a significant correlation between stress and the reaction of the autonomic nervous system. It is necessary to prevent the disturbance of the adaptive of the body. Therefore, we must create a safe environment for the health of students. It is desirable to reduce the time spent in the information space (up to 80 minutes, followed by a break). Since the research conducted on a small sample and one educational institution, it is necessary to research this issue on a larger representative sample.
\end{abstract}

\section{Introduction}

The sustainability of the development of society is ensured not only by the introduction of innovative technologies, the quality of training but, most importantly, by the safety of the health of human capital. The intensive introduction of information technologies into education characterized by a multi-complex of stimuli that negatively affect various organs and systems of students $[12 ; 28]$. A low level of mobility leads to hypoxia and hypodynamia. As a result, the development of respiratory acidosis and impaired activity of the cardiovascular system noted. At present, the influence of informatization on the functional

\footnotetext{
* Corresponding author: bashkireva32@gmail.com
} 
state of the organism as a whole. In addition, it is not enough to study the effect on the visual analyzer, hand motility, cognitive sphere, and metabolic processes [1; 4-10; 24].

An adaptive response considered as an adaptation of the functional state to changing environmental conditions. of an organism or its structures to changing environmental conditions [2]. Often, adaptive responses or adaptive response identified with the concept of physiological and psychological "stress". The conception of "stress" is associated with the name of G. Selye. From a physiological point of view, he considered stress as a non-specific reaction of the body to any requirement presented to it, which he called the "adaptation syndrome" (GAS) [26; 27]. He identified three stages of GAS, each of which is associated with changes in nervous and endocrine functioning: anxiety response, resistance stage, exhaustion stage.

The study of adaptive psychological reactions of a person in stressful situations is especially relevant. Psychological responses to stress are significantly more complex. J. McGraft (1976) believed that stress is a significant imbalance between the demand for a situation and the body's ability to react to it [11]. In recent years, the concepts of "mental stress" and "emotional stress" have begun to appear more and more often. Their content began to include initial emotional reactions, emotional-mental syndromes, and affective reactions. It believed that reaction could be specific and require metabolic activity [3;22]. Interpersonal relationships can cause emotional stress and cause marked changes in the chemistry of blood or urine.

Many specialists and researchers tend to equate biological stress with nervous overload, emotional stress. There is an opinion that the common denominator of all stressors is the activation of the physiological apparatus responsible for emotional arousal that occurs when threats or unpleasant facts in a life situation.

Researchers identify concepts of adaptive response: compensation, neural plasticity, cognitive flexibility [27]. According to others, the adaptive response includes such a component as the body's sensitivity to external influences $[19 ; 21]$. Hyper- or hyposensitivity to various content can cause unfavourable reactions of functional systems (disruption of the body's adaptive systems). In this case, medical or recreational rehabilitation is necessary [17]. Another component involves the response to the pathogen and entails the individual resistance of the organism. Long-term exposure to a pathogen can lead to the development of various diseases or the pathology of many physiological systems.

When mastering their professional activities, students and teachers use modern information and communication technologies [14]. That is due to the emergence of the global Internet network, its penetration into all spheres of society [25]. The processes of globalization of education lead to changes in teaching methodology [18]. There are new methods, techniques, forms of education focused on the use of information and communication technologies: virtual lectures, virtual seminars, workshops [15-16].

As the period of the COVID-19 pandemic has shown, the era of rapid informatization has begun, including in the context of mastering professional activities in educational organizations. However, for such educational content, harmless hygienic training standards not developed. Especially if distance mode or online using [23].

Certainly that the development of professional activity is a social phenomenon and ensures the sustainability of the development of society [13]. Boys and girls choose a profession based on its social significance. In our work, we have chosen the concept of gender differences in adaptive reactions of students in the context of mastering information technologies in higher education. The gender in this aspect indicates the social role of boys and girls, conditioned by the training of one profession, in which they will have to fulfil general social roles [20]. The development of hygienic labour standards in the scope of technocratization is a significant factor in the health safety of future professionals. Its foundations laid in the conditions of mastering the profession. And the question arises, are 
there gender differences in the adaptive responses of students to the development of educational information innovations?

In connection with the above, the work aimed to study gender differences in adaptive reactions of students in the context of mastering educational innovations as a significant aspect of health safety of future specialists and sustainable development.

\section{Method}

The work used non-invasive methods of studying the adaptive responses of the cardiovascular system to the impact of ICT in the context of academic studies at a university.

The methodology of heart rate variability successfully used in modern studies to assess the state of the body's regulatory systems. HRV considered as a result of the activation of various regulatory mechanisms that maintain cardiovascular homeostasis. Its study allows one to obtain information about the tension of regulatory gear in distinct conditions of human activity.

The Institute for the Implementation of New Medical Technologies "RAMENA" (Ryazan) has developed a specialized software and hardware complex "Varicard", recommended by the Ministry of Health of Russia as a standard tool for the study of heart rate variability in clinical practice, physiology and applied psychology. The complex provides the implementation of all the main methods of HRV analysis (statistical analysis, variational heart rate monitoring, correlation, rhythmography, autocorrelation, spectral analysis).

The paper analyzes such indicators of HRV as HR - heart rate; RMSSD - the activity of parasympathetic, AMo - sympathetic link of autonomic regulation of heart rate control; SI is the degree of tension in regulatory systems (stress index); spectral analysis (HF, LF, VLF in\%) - as indicators of autonomic response; VLF / HF - metabolism.

The results processed with the calculation of basal mathematical and statistical data, graphs built using the software "Statistica6.1", "ISCIM6.0". The significance of the differences and the correlation carried out take into account the lognormal distribution of the analyzed indicators. It noted that the methodological principle of "Occam's razor" allows the simple explanation to consider correct if there are logically consistent explanations of any phenomenon.

The measurements taken at rest during the classroom sessions using ICT. It investigated 58 students (boys - 30; girls - 28) - all of the study in different faculty.

\section{Results and discussion}

A comparative analysis of heart rate measurements among the surveyed students showed that $46.7 \%$ of boys and $45.5 \%$ of girls had tachycardia during the lessons. The average HR in the sample among boys was $83.0 \pm 3.1 ; \pm \sigma=16.0$, and for girls $83.6 \pm 3.4 ; \pm \sigma=15.2$. According to this indicator, no significant differences found between boys and girls. But it noted that long-term exercises, more than 1 hour and 30 minutes, cause an increase in heart rate. During this time, a stable "risk" group revealed among boys - 20\%, among girls - 25\%. In these groups, the pulse from the beginning to the end of the exercise observed above 84.5 beats/min.

A significant relationship revealed between the stress indexes (SI) and the parameters of the activity of the parasympathetic (RMSSD) and sympathetic (AMo) links of autonomic regulation (tab.1). 
Table 1. The relationship between the indicators of autonomic regulation of heart rate control and stress index among students in the classroom in the context of the use of information innovations

\begin{tabular}{|c|c|c|c|}
\hline Indicators & Gender & RMSSD log & AMo log \\
\hline \multirow{2}{*}{ SI $\log$} & young men & 0,96 & $-0,89$ \\
\cline { 2 - 4 } & girls & $-0,76$ & 0,92 \\
\hline
\end{tabular}

In young men, during intensive work in conditions of information technologies, the reactions of the parasympathetic and sympathetic systems have a significantly high correlation with the stress index (SI). Consequently, the longer the exposure of young men to ICT, the higher the stress level. And the degree of influence of the vagus nerve on the control of the heart rate increases. Under these conditions, girls have a high level of relationship between the stress index and the activity of the sympathetic link in the regulation of heart rate control. The higher the stress level, the greater the influence of the sympathetic system on heart rate control in girls.

The study of spectral characteristics revealed that in the classroom with the use of ICT, the HF $(\%)$ was significantly lower for boys than for girls $(\mathrm{t}=2.18 ; \mathrm{P}<0.05)$. However, $\mathrm{LF}$ $(\%)$ is significantly higher in boys $(\mathrm{t}=3.05 ; \mathrm{P}<0.01)$. There were no significant differences in VLF (\%). It stated that in conditions of employment with the use of ICT as an educational innovation, young men experience tension in the cardiovascular centre. That accompanied by severe hypoxia. And for girls - by the tension of the emotional sphere. Synchronization of heart rhythm control in boys achieved by low-frequency waves and in girls by high-frequency waves (Fig. 1).

Indicators of spectral analysis (\%) of HRV in boys $(\mathrm{m})$ and girls $(\mathrm{f})$ in the context of mastering ICT

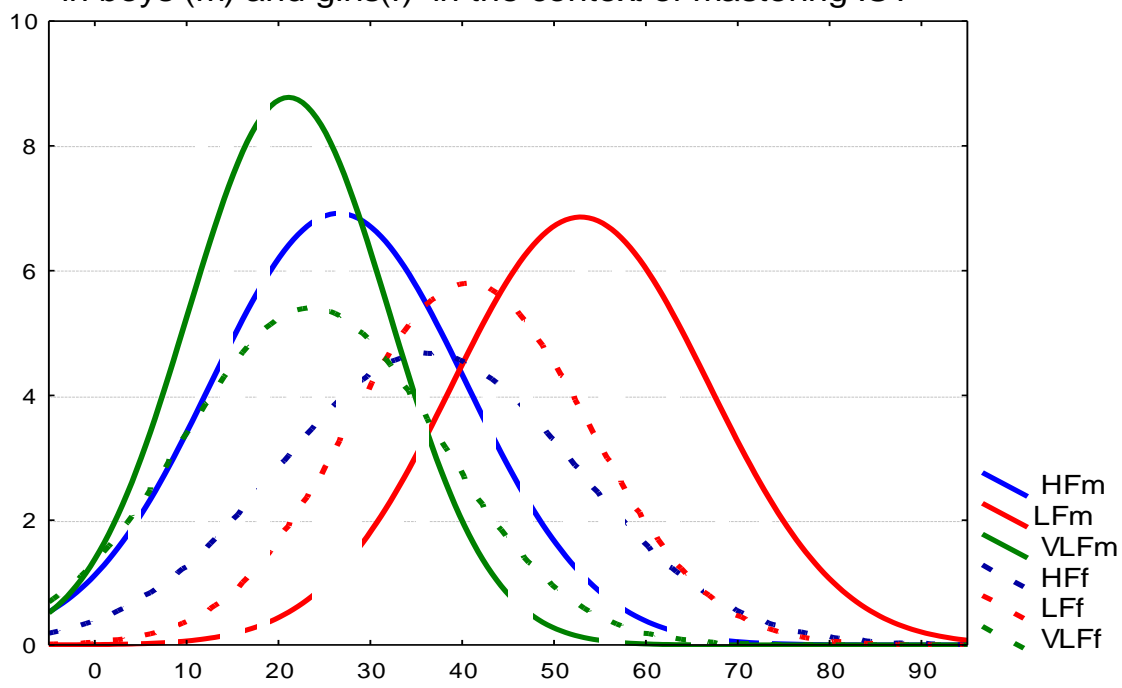

Fig. 1. Indicators of spectral analysis (\%) of HRV in boys (m) and girls (f) in the context of mastering ICT

The relationship between VLF and HF (VLF / HF) plays a role as a marker of metabolism in the body. Under the studied conditions, a low metabolic rate found in $20 \%$ of boys and $21.7 \%$ of girls, and a high level of energy consumption found in $10 \%$ of boys and $10.7 \%$ of girls.

However, we are inclined to believe that in the study of the adaptive reactions of the organism to the influence of any social factors, individual differences take into account. That 
is because under stress conditions, for example, prolonged exposure to ICT, both mobilization and depletion of adaptive systems will be observed, depending on the capabilities and resources of a particular organism (Fig. 2-3).

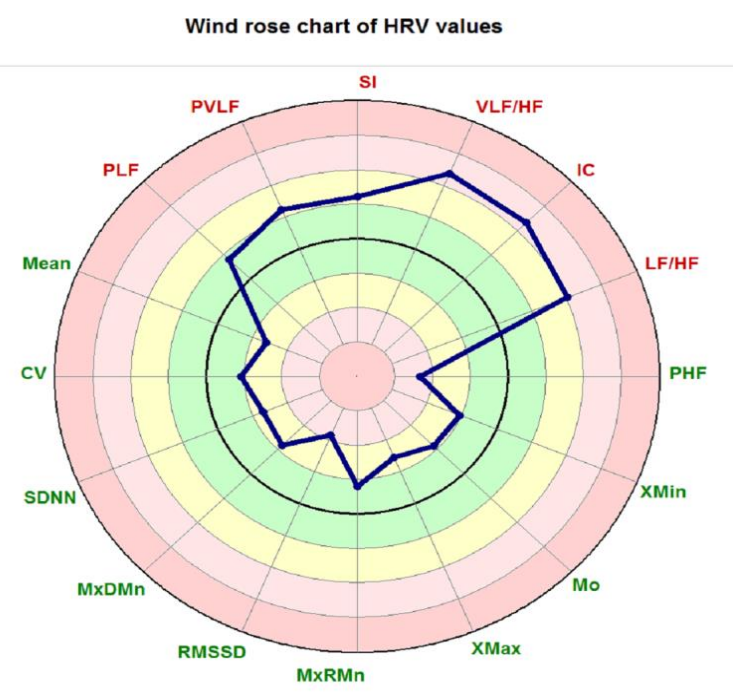

Fig. 2. Individual adaptive reactions of $H R V$ of a young man in the conditions of mastering ICT in the classroom

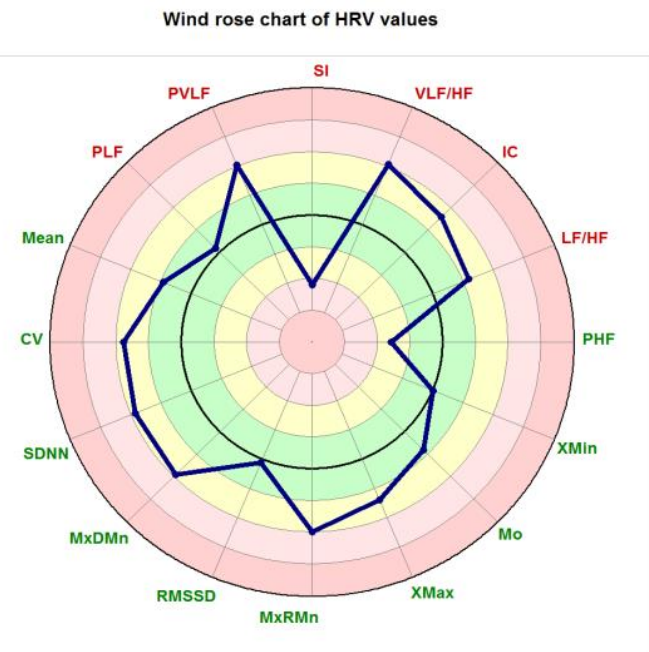

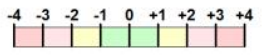

Fig.3. Individual adaptive reactions of HRV in a girl in terms of mastering ICT in the classroom

Studies showed that the adaptive responses of the cardiovascular system in both boys and girls to the impact of ICT have a wide individual range. 


\section{Conclusion}

The use of a non-invasive method of heart rate variability in our study led to the identification of gender, sex and individual differences in the adaptive reactions of students to the intensive use of ICT as an educational innovation.

Comparative analysis of heart rate monitoring revealed persistent tachycardia during the lessons in the surveyed male and female students. Observations have shown that long-term sessions using ICT, more than 1 hour and 30 minutes, cause an increase in heart rate. During this time, a stable "risk" group established among boys - 20\%, girls - 25\%. In these groups, the pulse from the beginning to the end of the exercise observed above 84.5 beats $/ \mathrm{min}$.

Under the conditions of mastering information technologies introduced into education, in boys, an increase in the stress index observed, which was reliably associated with the tension of the parasympathetic system, and in girls - the sympathetic system of regulation of heart rhythm control. This fact testifies biological (sex) differences in adaptive responses to the implementation of information technologies into education.

Metabolism plays a significant role in the successful adaptation of the organism to the negative influences of stress factors of different nature. The study of the relationship between $\mathrm{VLF} / \mathrm{HF}$ revealed that $30 \%$ of boys and $32.4 \%$ of girls have negative individual differences in ensuring the flow of adaptive reactions to the influencing factor. However, in both boys and girls, metabolism considered a marker that stimulates the activity of adaptive responses of the autonomic nervous system, which controls the heart rate under conditions of ICT use.

Synchronization of heart rate control in boys achieved by low-frequency waves and in girls by high-frequency waves. It stated that in the conditions of classes with the uses of ICT as an educational innovation, young men show tension in the cardiovascular centre, accompanied by severe hypoxia, and girls - tension in the emotional sphere. The data obtained characterize gender differences in adaptive responses. It found that the adaptive reactions of the cardiovascular system in both boys and girls to the impact of ICT have a wide individual range.

Thus, the research using the HRV method showed that adaptive responses to the introduction of educational innovations characterized not so much by gender as by gender. It understood that gender differences affect the implementation of social roles in any conditions of the life of society. It is impossible to change the evolutionary mechanisms of adaptation of the mid-vascular system of men and women to the impact of any factors, including social ones. We believe that gender differences in adaptive responses can observe in the reliability of correlations. Thus the relationship between the indicator of stress and the reaction of the autonomic nervous system. In young men in a stressful situation, protective inhibition activated under the influence of the vagus, and in girls, the psychoemotional sphere activation result from the activity of the sympathetic division of the autonomic nervous system. It is necessary to prevent the possibility of disruption of the adaptive system. It is desirable to reduce the training time in an information environment to 80 minutes. Take a break. That evidenced by the data obtained by us on the indicator of heart rate monitoring.

The implementation of sustainable development of modern society depends on the determination of not only gender differences but also sex. The Labor and educational activity of a person involves adaptive reactions to the impact of any social factors. It also noted that the research results carried out on a small sample of one educational institution. A deeper study of this issue on a larger representative sample assumed. 


\section{References}

1. M. Baer, M. Frese, Journal of Organizational Behavior. 24 (1), 4568 (2003)

2. H.G. Brown, M.S. Poole, T.L. Rodgers, Journal of Management Information Systems, 20 (4), 115137 (2004)

3. A. Carmeli, Long Range Planning, 40 (1), 3044 (2007)

4. C.C. Chen R.S. Shaw, Journal of Distance Education Technologies, 4 (4), 88103 (2006)

5. C.-M.Chiu, M-H. Hsu, S.-Y. Sun T.-C. Lin, P-C. Sun, Computers \& Education, 45 (4), 399416 (2005)

6. A.E. Colbert, M.K. Mount, J.K. Harter, L.A. Witt, M.R. Barrick, Journal of Applied Psychology, 89, 599609 (2004)

7. A.C. Edmondson, Sage Journals. 44 (2), 350383 (1999)

8. A.C. Edmondson, Journal of Management Studies. 40 (6), 14191452 (2003)

9. A.C. Edmondson, Trust and distrust in organizations: Dilemmas and approaches, Russell Sage Foundation, (2004)

10. A.C. Edmondson, R.M. Bohmer, P.G. Pisano, Administrative Science Quarterly, 46 (4) $685716(2001)$

11. Erstad O. (2013) Digital learning lives: Trajectories, literacies, and schooling, New Literacies and Digital Epistimiologies.

12. Maslow A. (1968) Toward a Psychology of Being, 2nd ed., New York: Van Nostrand Reinhold.

13. D.J. McAllister, Academy of Management Journal, 38 (1) 2459 (1995)

14. J.A. McCarty, L.J.Shrum, Public Opinion Quarterly, 64 (3), 271298 (2000)

15. T. Mooij, Computers \& Education, 42 (1), 2544 (2004)

16. T. Mooij, E. Smeets, Computers \& Education, 36 (3) 265281 (2001)

17. K.J. Valadares, Health Care Manager, 23 (3) 220224 (2004)

18. G. R. Jones, J. M. George, The Academy of Management Review 23, 3 (1981)

19. G. R. Slemp, J. G. Field, A. S-H. Cho, Journal of Vocational Behavior, 121 (2020)

20. Genia V. (1997), Review of Religious, 38 (4) 344361 (1997)

21. W.A.Kahn, The Academy of Management Journal, 33(4), 692724 (1990) R.J.Lawrence, S. B. Sells, Toward A Psychology of Situations, 22 (1981)

22. L. L. Martins, F.W. Kellermanns, Academy of Management Learning \& Education, 3(1), 7 (2004)

23. D.R. May, R.L. Gilson, L.M. Harter, Journal of Occupational and Organizational Psychology, 77, 1137 (2004)

24. M. van Raaij E., Schepers J, Computers \& Education, 50, 838852 (2008)

25. H. Selye, Nature. 138, 32 (1936)

26. H. Selye, Journal of Clinical Endocrinology, 6, 117230 (1946)

27. J. Sweller, Implications of cognitive load theory for multimedia learning (New York: Cambridge University Press, 2005) 